\title{
A comparative Study on Intermediate Public Examination 2013 - 14 of Andhra Pradesh by Data Envelopment Analysis
}

\author{
Naga Anuradha Chengalvala ${ }^{1}$ \\ Assistant Professor, \\ Vasavi College of Engineering, Hyderabad, \\ Telangana State, India \\ Raju Nellutla ${ }^{2}$ \\ ${ }^{2}$ Associate Professor, \\ Guru Nanak Institutions Technical Campus, \\ Hyderabad, Telangana State, India
}

\author{
V V Haragopal ${ }^{3}$ \\ Professor, Department of Statistics, \\ Osmania University, Hyderabad, \\ Telangana State, India \\ Shahnaz Bathul ${ }^{4}$ \\ Professor, \\ Department of Mathematics, JNTU, Hyderabad, \\ Telangana State, India
}

\begin{abstract}
In this Paper we analyze the Board of Intermediate Public Examination data by Data Envelopment Analysis for the state of Andhra Pradesh in the academic year 2013-14 to see the Pattern of Efficiencies and Performance of the districts in Andhra Pradesh state prior to the dissection of state in to two states. The Performance of the districts is presented along with the Peer Districts Performance of the state as whole.
\end{abstract}

Keywords: Data Envelopment Analysis, Technical Efficiency, Performance, Peers, Potential Improvement.

\section{INTRODUCTION}

For several years, many applied fields share common concern over design and action on how to improve the data analytics. The concept of best practices is to purposeful action in Private and Government sectors for improvement. There are three significant characteristics connected with a "best practice": a comparative process, an action and a link between an action and some outcomes or goals. From 1980's on wards, researchers started to direct their efforts towards extending "best practice" to Education. This led to school improvement initiatives and studies on the characteristics of School milieu conductive to learning (Rutter \& Maughan, 2002). In different parts of the world Researchers like Rhodes, Cooper and Thanassoulis started seeking proper measurement methodologies for school efficiency. Rodhes and Southwick (1986) studied about the efficiency in U.S.A. Private Universities in comparison to the Public Universities, to analyze the data by applying Data Envelopment Analysis Model and they regarded as Decision Making Units on the university as whole.

Kwimbere (1987) also applied DEA model to appraise the performance of Decision Making Units viz., Engineering, Mathematics and Physics departments of a set of universities in U.K. ,Raju Nellutla and Haragopal(2015) review the Performance of Management Schools in Secondary School Examinations in the academic years 2009-10 and 2010-11 for the state of Andhra Pradesh by Data Envelopment Analysis.

In this schoolwork we analyze the case of Board of Secondary Education (BSE) in Andhra Pradesh to levy which district fares well for the data collected for the academic year 2013-14by DEA.

\section{DAta EnVelopment Analysis}

Data Envelopment Analysis is reasonably "data oriented" approach for evaluating the performance of a set of peer entities called decision making entities, Which convert various inputs in to various outputs .In the recent years, the DEA has emerged in to a greater array of application for using evaluating the performance of several kinds of entities engaged in many different activities in many dissimilar contexts in many different countries world over. Goverdhan, Raju Nellutla and Haragopal 
(2016) perform the significant Data Envelopment Analysis of Hospital efficiency in India and found interesting results in health care issues.

In this study we consider Data Envelopment analysis (DEA) is used in an challenge to deal with the issue of measuring the relative efficiency of the districts in Andhra Pradesh and Telangana .The technique DEA was engaged for the multiple inputs and outputs for evaluating the outline measure of efficiency of the data. These evaluation can be conducted not only at the society level but also in sub units such as number of boys and girls appeared in examination and their results.

2.1 Educational Inputs: The resources or effort indicators are units of measurement, which correspond to the factors used to carry out the delivery of services. The identification and measurement of these factors is crucial in a fair evaluation of the economy and effectiveness in the programs and services management. Previous studies on other performance models (Johnes 1996) have shown that efforts of universities can be categorized in various ways. Here Educational Inputs are district wise number of Boys and Girls appeared in Public Examination.

2.2 Educational Outputs: Output indicators compute the level of bustle of programs and services. Furthermore, it is always useful to reveal the indicators that provide information about the capacity and the quality of the activity (Pina \& Torres 1995). The quality, as a feature that affects the user's acuity, can also modify the productive process input/output relation. For this reason, it must be measured to contact the efficiency of the process. Subramanyam and Reddy (2008) constructed DEA methodology to review the risk of commercial Banks., Raju Nellutla and Haragopal (2015) constructed Data Envelopment Analysis to know the Performance of the districts in SSC Public Examinations for the years 2009 - 2011 of Andhra Pradesh. In our study we give the Educational outputs of the Public Examination is Number boys and girls passed out in public Examination.

\section{EFFICIENCY}

The efficiency analysis is always evaluated to assess the performance of an institute. The Efficiency is an important factor in profitable analysis, where the process has a single input and single output, then Efficiency is defined as:

$$
\text { Efficency }=\frac{\text { Output }}{\text { Input }}
$$

The theory of construction from the economic point of view then it can be considered as a proper model to link inputs and outputs, This theory has several strengths. First, some formal affiliation between inputs and outputs exists and a " best practice " can be identified by comparing different units transforming in to inputs to outputs somewhere all units are assessed comparative to that of optimum. The production process that occurs in Junior colleges seems to have the same properties of the above economic model in the business sector- consumption of physical and human resources as inputs to work out outputs as shown in below.

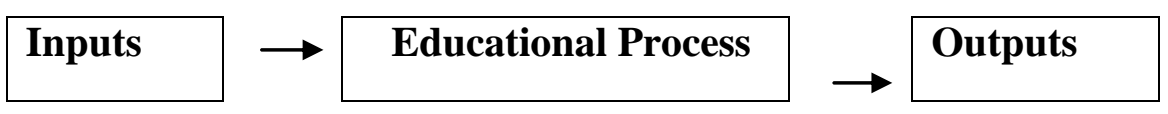

Figure 1. Transformation Input/ Output Process

3.1 The CCR Model: In Data Envelopment Analysis( DEA) the most broadly used model is CCR Model( Banker et al ., 1989; Charnes et al.,1993). A Constant Return To Scale connection is implicit between Inputs and Outputs. It was the First Data Envelopment Analysis model to be urbanized CCR after Charnes, Cooper and Rhodes who introduced this model in article published in European Journal of Operations Research (1978). This model compute the Overall Efficiency (OE)for each unit, Where the both Technical Efficiency and Scale Efficiency are aggregated in to single value.

The primitive CCR model is explained as follows

Decision Making Units $\mathrm{DMU}_{\mathrm{j}}$ : The $\mathrm{j}^{\text {th }}$ Decision Making Unit $\mathrm{j}=1,2,3, \ldots, \mathrm{n}$

$x_{\mathrm{ij}}$ : The amount of the $\mathrm{i}^{\text {th }}$ input of the $\mathrm{j}^{\text {th }}$ DMU $\mathrm{x}_{1 \mathrm{j}}, \mathrm{x}_{2 \mathrm{j}}, \mathrm{x}_{3 \mathrm{j}}, \ldots, \mathrm{x}_{\mathrm{nj}}$

$y_{i j:}$ The amount of the $\mathrm{j}^{\text {th }}$ output of the $\mathrm{j}^{\text {th }} \mathrm{DMU} \mathrm{y}_{1 \mathrm{j}}, \mathrm{y}_{2 \mathrm{j}}, \mathrm{y}_{3}, \ldots, \mathrm{y}_{\mathrm{sj}}$

$\mathrm{v}_{\mathrm{i}}$ : The weight assigned to the $\mathrm{i}^{\text {th }}$ input $\quad \mathrm{i}=1,23, \ldots, \mathrm{m}$ 
$\mathrm{u}_{\mathrm{r}}$ : The weight assigned to the $\mathrm{r}^{\text {th }}$ output $\mathrm{r}=1,23, \ldots, \mathrm{s}$

The Fractional Programming Problem ( FPP) is :

Maximize $\mathrm{Z}=\frac{u_{1} y_{1 k}+u_{2} y_{2 k}+\cdots+u_{s} y_{s k}}{v_{1} x_{1 k}+v_{2} x_{2 k}+\cdots+v_{m} x_{m k}}$

Subject to Constraints: $\frac{u_{1} y_{1 j}+u_{2} y_{2 j}+\cdots+u_{s} y_{s j}}{v_{1} x_{1 j}+v_{2} x_{2 j}+\cdots+v_{m} x_{m j}} \leq 1 \mathrm{j}=1,2, \ldots, \mathrm{n}$

and Non negativity $u_{1}, u_{2}, u_{3}, \ldots, u_{s} \geq 0 \quad v_{1}, v_{2}, v_{3}, \ldots, v_{m} \geq 0$

The proportion of input and output should not surpass 1 for every decision making unit. The objective is to Maximize the Decision Making Units. The optimal value of $\mathrm{R}^{*}$ is at most one. Mathematically, non negativity constraints (4) is not enough for the fractional terms in(3) to have a positive value. Now we replace the Factional Program (FP) by the following Linear Programming Problem (LPP),

Maximize $Z(u, v)=u_{1} y_{1 k}+u_{2} y_{2 k}+---+u_{s} y_{s k}$

Subject to $v_{1} x_{1 j}+v_{2} x_{2 j}+---+v_{m} x_{m j}=1$

$u_{1} y_{1 j}+u_{2} y_{2 j}+---+u_{s} y_{s j} \leq v_{1} x_{1 j}+v_{2} x_{2 j}+---+v_{m} x_{m j}$

$\mathrm{u}_{1}, \mathrm{u}_{2}, \mathrm{u}_{3}, \ldots, \mathrm{u}_{\mathrm{s}} \geq 0 \quad, \mathrm{v}_{1}, \mathrm{v}_{2}, \mathrm{v}_{3}, \ldots, \mathrm{v}_{\mathrm{m}} \geq 0$

Optimal Solution $\left(\mathrm{v}^{*}, \mathrm{u}^{*}, \mathrm{Z}^{*}\right)$

The reference set

$R_{s}=\left\{j: \sum_{r=1}^{S} u_{r}^{*} y_{r j}=\sum_{i=1}^{m} v_{i}^{*} x_{i j} j=1,2,3, \ldots, n\right\}$

The Reference set $R_{s}$ is the Primal Problem. The Primal Problem becomes

$\operatorname{Maximize} Z^{*}\left(v^{*}, \mathrm{u}^{*}\right)=\sum_{r=1}^{s} u_{r} y_{r k}$

Subjecttoconstraints: $\sum_{r=1}^{s} u_{r}^{*} y_{r j}-\sum_{i=1}^{m} v_{i}^{*} x_{i j} \leq 0 j=1,2,3, \ldots, n$

$\sum_{i=1}^{m} v_{i} x_{i k}=1$

$$
\text { Non negativity } \quad v_{i} \geq 0 \quad u_{r} \geq 0
$$

The above mentioned linear Programming Problems capitulate the Optimal Solution $Z^{*}$, where efficiency score is called Technical Efficiency or CCR Efficiency for the meticulous $D U_{j}$ and Efficiency scores for all of them are obtained by repeating them for each $\mathrm{DMU}_{j}, \mathrm{j}=1,2, \ldots . \mathrm{n}$. The value of $Z^{*}$ is always less than or equal to unity. DMUs for which $Z^{*}<1$ are comparatively inefficient and those for which $Z^{*}=1$ are relatively efficient, having their realistic input-output combination points on the frontier(boundary). The frontier itself consists of linear facts spanned by proficient units of the data, and the resulting frontier production function has no indefinite parameters. As per the above model we put into operation empirical model evaluation for the data considered in the next section by illumination the Potential Improvement (P.I) and Reference Comparison (R.C) . We initially explained about Potential Improvement (P.I) and Reference Comparison (R.C) .

3.2 Potential Improvement: An efficient cram not only provides an efficiency score per each unit but also indicates by how much and in which areas an inept unit need to develop in order to efficient. This information can facilitate the targets to be set which could help inept units to be improved in their Performance.

3.3 Reference Comparison: If the assessment of units was found as ineffective then it is felt to be defensible then the information provided can be used as a basis for setting targets for the units.As a primary step in setting targets, the bungling unit should be compared with the units in its reference set.

3.4 Peer Group: Data Envelopment Analysis identifies for each incompetent unit a set of exceptional units, called Peer Group, which includes those units that are efficient if evaluated with the optimal weights of ineffective unit. The Peer Group, made up of Decision Making Units which are characterized by working methods similar to the inefficient unit being examined, which is a pragmatic term of comparison which unit aim to emulate in order to improve its performance. 
3.5 Constant Returns to Scale: The efficiency measures are based on Constant Returns to Scale technology (CRS). This shows that the production technology under consideration is such, that an increase in all the inputs by some amount results in an increase in all the outputs by the same amount. The variable takings to scale result in a impartial change (increase or decrease) in the outputs. The three types of returns to scale and the variation between the input-reducing and the output-increasing measures are illustrated on figures by allowing for the Decision Making Units (DMUS) A,B,C\& D.

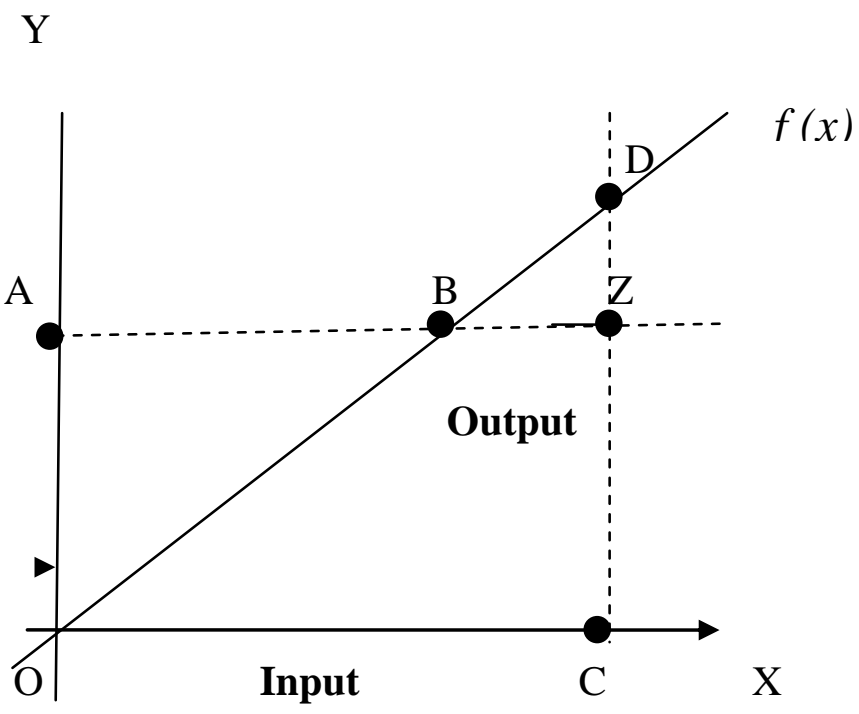

Figure 2. Constant Returns to Scale

From the above figure we recognize that, a production of a single output is illustrated graphically. In fig (2) it can be seen that the function $\boldsymbol{f}(\boldsymbol{x})$, where $\boldsymbol{f}(\boldsymbol{x})$ is a straight line and has a single slope. Hence, for each unit raise in the input that goes into the process, the output produced increases by a stable proportional quantity; hence it represents Constant Returns to Scale (CRS).

In this case, $\mathrm{Z}$ could be projected onto the frontier either beneath an input- reducing consideration or an output - increasing consideration. B and D are projected points on the frontier obtained for comparison.

\section{EMPIRICAL STUDY}

It is renowned that every state in India holds a Public Examination at $12^{\text {th }}$ grade. This data was selected to see the Efficiency/ Peer Performance of the 23 districts of Andhra Pradesh. The Inter Public Examinations data for the academic year 2013-2014 of Andhra Pradesh in the 23 districts were considered the data further separated in to Andhra Pradesh 13 districts and Telangana 10 districts for Measuring the Efficiency of the Two States in Board of Intermediate Education, Inter Public Examinations, March, 2014.

In Inter Public Examinations (IPE), March, 2014, 801419 Regular Candidates have appeared for Examinations. Out of 801419 candidates, 413098 boys and 388321girls Candidates have appeared for Inter Public Examinations.

The results of Data Envelopment Analysis (DEA) for unified Andhra Pradesh are presented below:

Table 1. District wise Technical Efficiency of the United Andhra Pradesh

\begin{tabular}{|c|c|c|c|c|c|c|}
\hline S.No & District & Score & Technical Efficiency & References & Peers & Name of the Peers \\
\hline 1 & Adilabad & $71.80 \%$ & 0.718 & 0 & 2 & Krishna, West Godavari \\
\hline 2 & Anathapur & $85.20 \%$ & 0.852 & 0 & 2 & Krishna, West Godavari \\
\hline 3 & Chitoor & $91.30 \%$ & 0.913 & 0 & 2 & Krishna, West Godavari \\
\hline 4 & East Godavari & $95.60 \%$ & 0.956 & 0 & 1 & West Godavari \\
\hline 5 & Guntur & $91.20 \%$ & 0.912 & 0 & 1 & West Godavari \\
\hline
\end{tabular}


A comparative Study on Intermediate Public Examination 2013 -14 of Andhra Pradesh by Data Envelopment Analysis

\begin{tabular}{|c|c|c|c|c|c|c|}
\hline \hline 6 & Hyderabad & $92.30 \%$ & 0.923 & 0 & 2 & Krishna, West Godavari \\
\hline 7 & Kadapa & $87.40 \%$ & 0.874 & 0 & 2 & Krishna, West Godavari \\
\hline 8 & Karim Nagar & $91.00 \%$ & 0.910 & 0 & 1 & West Godavari \\
\hline 9 & Khammam & $87.60 \%$ & 0.876 & 0 & 2 & Krishna, West Godavari \\
\hline 10 & Krishna & $100.00 \%$ & 1.000 & 22 & 0 & Krishna \\
\hline 11 & Kurnool & $86.10 \%$ & 0.861 & 0 & 1 & Krishna \\
\hline 12 & Mahaboob & $68.60 \%$ & 0.686 & 0 & 1 & Krishna \\
\hline 13 & Nagar & & 0.668 & 0 & 2 & Krishna, West Godavari \\
\hline 14 & Nalgonda & $73.30 \%$ & 0.733 & 0 & 2 & Krishna, West Godavari \\
\hline 15 & Nellore & $94.30 \%$ & 0.943 & 0 & 1 & Krishna \\
\hline 16 & Nizamabad & $76.00 \%$ & 0.760 & 0 & 2 & Krishna, West Godavari \\
\hline 17 & Prakasam & $85.90 \%$ & 0.859 & 0 & 1 & Krishna \\
\hline 18 & Ranga Reddy & $92.50 \%$ & 0.925 & 0 & 1 & Krishna \\
\hline 19 & Srikakulam & $84.80 \%$ & 0.848 & 0 & 2 & Krishna, West Godavari \\
\hline 20 & Vishakhapatnam & $96.40 \%$ & 0.964 & 0 & 1 & Krishna \\
\hline 21 & Vizia Nagaram & $87.30 \%$ & 0.873 & 0 & 2 & Krishna, West Godavari \\
\hline 22 & Warangal & $75.90 \%$ & 0.759 & 0 & 2 & Krishna, West Godavari \\
\hline 23 & West Godavari & $100.00 \%$ & 1.000 & 16 & 0 & West Godavari \\
\hline
\end{tabular}

From the above Table1 The Technical Efficiency disparity for the 23 districts has the following bound0.668 $\leq Z^{*} \leq 1.000$. Also two districts have been emerged as efficient namely Krishna, West Godavari and the left over 21districts input loses due to CCR Technical competence. Potential enhancement is required in order to improve in their Performance with regards to results in this state of Andhra Pradesh.

From the Table 1 it is clear that Krishna and West Godavari are Technically (CCR) competent when compared to the 23 districts. It is observed that the Peers to the all other districts seem to be Krishna and West Godavari, Krishna district is having premier references. Peer contribution of this district is more comparable to other districts.

The Distribution of Scores Graph of Andhra Pradesh for the academic Year 2013-2014 is presented below:

\section{Histogram}

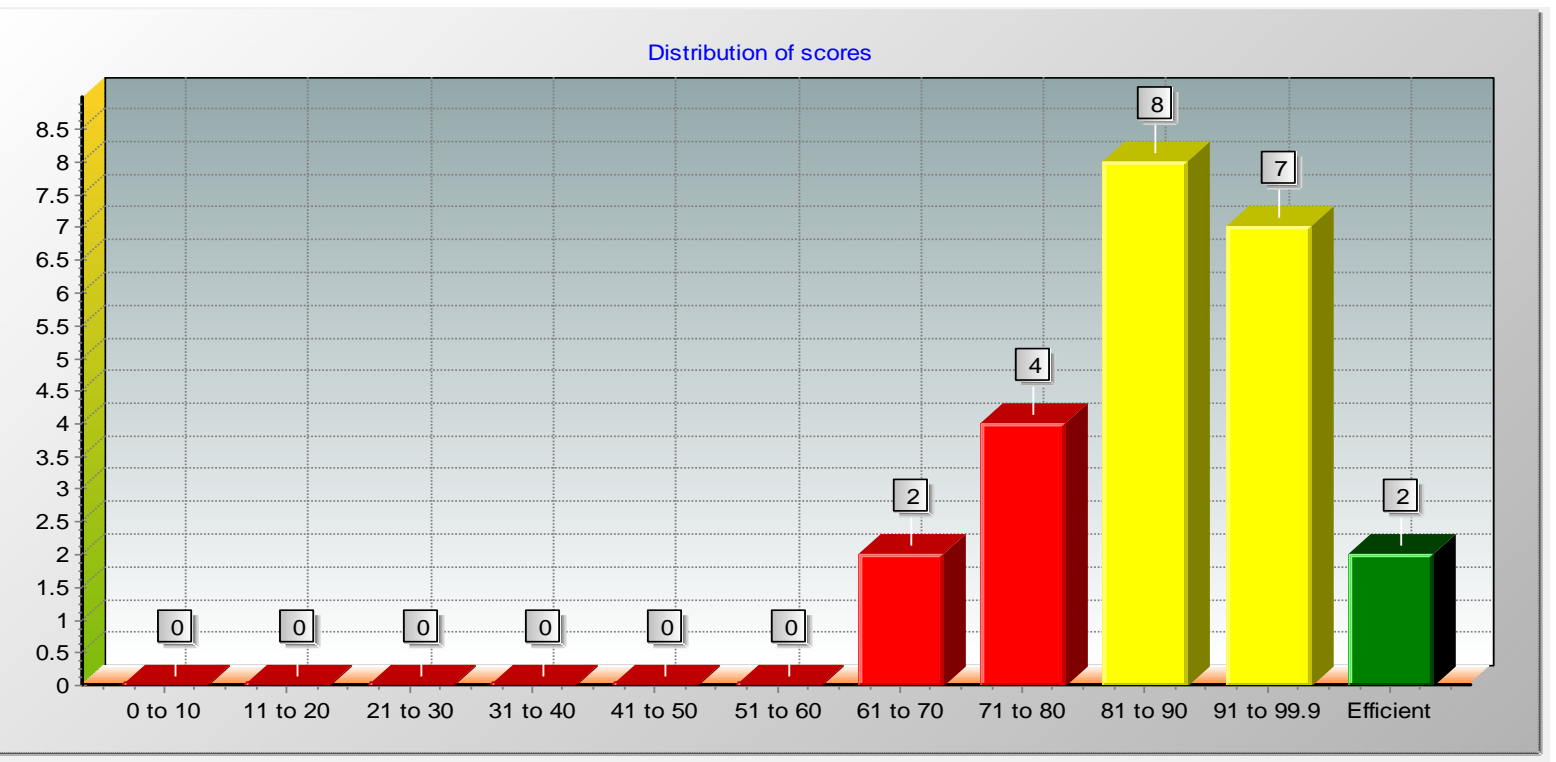

Figure 3. The Distribution of Scores Graph of Andhra Pradesh for the Year 2013-14 
Naga Anuradha Chengalvala et al.

The results of Data Envelopment Analysis (DEA) for divided Andhra Pradesh are presented below:

Table 2. The CCR Technical Efficiency of divided Andhra Pradesh

\begin{tabular}{|c|c|c|c|c|c|c|}
\hline S.No & District Name & Score & $\begin{array}{c}\text { Technical Efficiency } \\
\text { (CCR) }\end{array}$ & References & Peers & Name of The Peers \\
\hline 1 & Anathapur & $85.20 \%$ & 0.852 & 0 & 2 & $\begin{array}{c}\text { Krishna, West } \\
\text { Godavari }\end{array}$ \\
\hline 2 & Chitoor & $91.30 \%$ & 0.913 & 0 & 2 & $\begin{array}{c}\text { Krishna, West } \\
\text { Godavari }\end{array}$ \\
\hline 3 & East Godavari & $95.60 \%$ & 0.956 & 0 & 1 & West Godavari \\
\hline 4 & Guntur & $91.20 \%$ & 0.912 & 0 & 1 & Krishna \\
\hline 5 & Kadapa & $87.40 \%$ & 0.874 & 0 & 2 & $\begin{array}{c}\text { Krishna, West } \\
\text { Godavari }\end{array}$ \\
\hline 6 & Krishna & $100.00 \%$ & 1.000 & 11 & 0 & Krishna \\
\hline 7 & Kurnool & $86.10 \%$ & 0.861 & 0 & 1 & Krishna \\
\hline 8 & Nellore & $94.30 \%$ & 0.943 & 0 & 1 & Krishna \\
\hline 9 & Prakasam & $85.90 \%$ & 0.859 & 0 & 1 & Krishna \\
\hline 10 & Srikakulam & $84.80 \%$ & 0.848 & 0 & 2 & $\begin{array}{c}\text { Krishna, West } \\
\text { Godavari }\end{array}$ \\
\hline 11 & Vishakhapatnam & $96.40 \%$ & 0.964 & 0 & 2 & $\begin{array}{c}\text { Krishna, West } \\
\text { Godavari }\end{array}$ \\
\hline 12 & Vizia Nagaram & $87.30 \%$ & 0.873 & 0 & 2 & $\begin{array}{c}\text { Krishna, West } \\
\text { Godavari }\end{array}$ \\
\hline 13 & West Godavari & $100.00 \%$ & 1.000 & 8 & 0 & West Godavari \\
\hline
\end{tabular}

From the above Table 2 the Technical Efficiency disparity for the 13 districts has the following bound $0.848 \leq Z^{*} \leq 1.000$. Out of 13 districts only two has emerged as efficient namely Krishna, West Godavari the remaining 11 districts input loses due to Technical efficiency. Potential development is required in order to improve in their Performance with regards to results in this state of Andhra Pradesh.

From the Table 2 it is clear that Krishna and West Godavari are Technically (CCR) Efficient when compared to the 13districts. It is observed that the Peers to the all other districts look to be Krishna and West Godavari. Krishna district is having highest references. Peer contribution of this district is more equivalent to other districts.

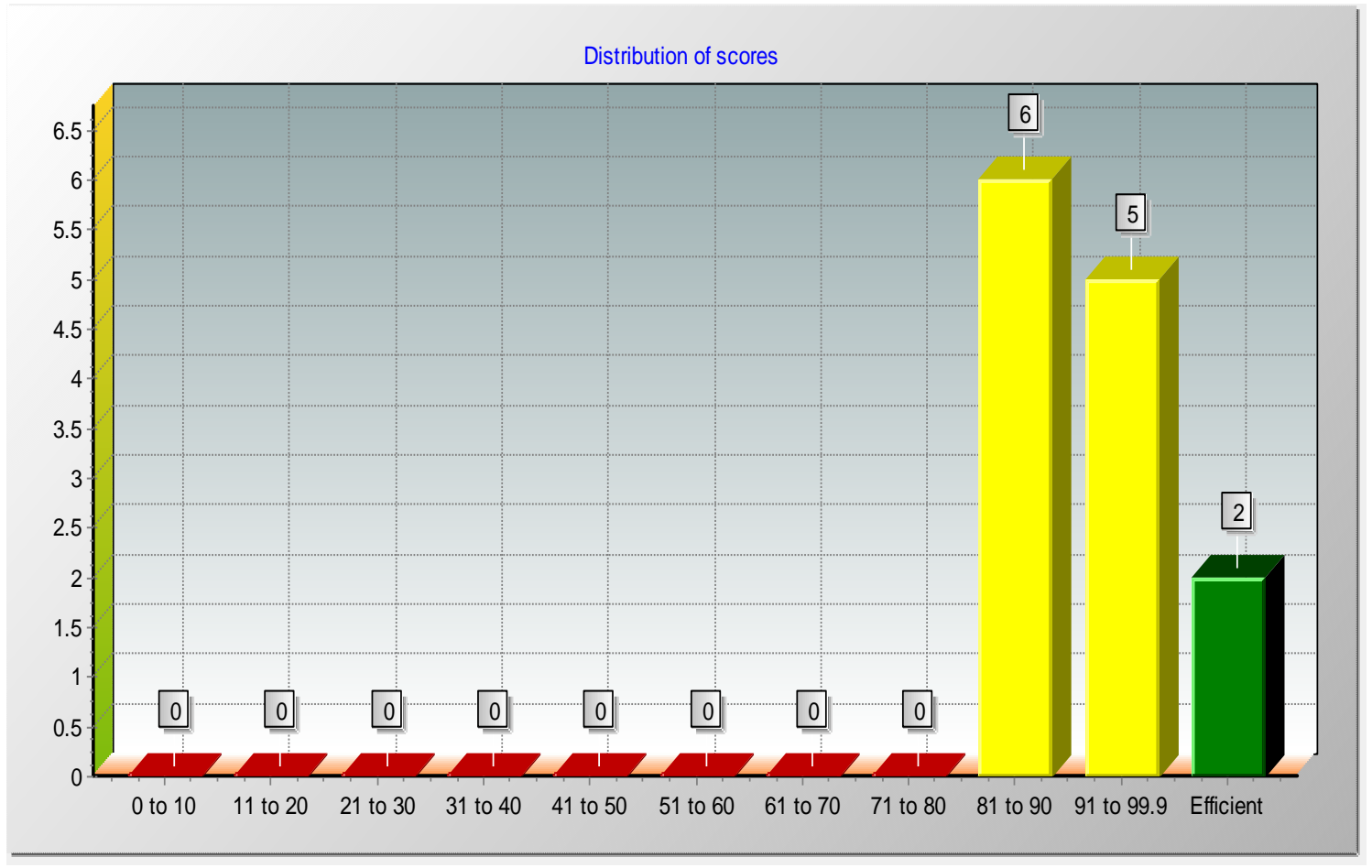

Figure 4. The Distribution of Scores Graph of divided Andhra Pradesh for the Year 2013-14 
A comparative Study on Intermediate Public Examination 2013 -14 of Andhra Pradesh by Data Envelopment Analysis

The results of Data Envelopment Analysis (DEA) for Telangana state are presented below:

Table 3. The CCR Technical Efficiency of Telangana State

\begin{tabular}{|c|c|c|c|c|c|c|}
\hline S.No & District Name & Score & $\begin{array}{c}\text { Technical Efficiency } \\
\text { (CCR) }\end{array}$ & References & Peers & Name of The Peers \\
\hline 1 & Adilabad & $78.50 \%$ & 0.785 & 0 & 2 & Karimnagar,Hyderabad \\
\hline 2 & Hyderabad & $100.00 \%$ & 1.000 & 6 & 0 & Hyderabad \\
\hline 3 & Karim Nagar & $100.00 \%$ & 1.000 & 6 & 0 & Karimnagar \\
\hline 4 & Khammam & $98.70 \%$ & 0.987 & 0 & 2 & $\begin{array}{c}\text { Ranga } \\
\text { Reddy,Karimnagar }\end{array}$ \\
\hline 5 & Mahaboob Nagar & $74.20 \%$ & 0.742 & 0 & 1 & Ranga Reddy \\
\hline 6 & Medak & $72.50 \%$ & 0.725 & 0 & 2 & $\begin{array}{c}\text { Ranga Reddy, } \\
\text { Hyderabad }\end{array}$ \\
\hline 7 & Nalgonda & $79.70 \%$ & 0.797 & 0 & 3 & $\begin{array}{c}\text { Ranga Reddy, } \\
\text { Karimnagar, } \\
\text { Hyderabad }\end{array}$ \\
\hline 8 & Nizamabad & $83.30 \%$ & 0.833 & 0 & 2 & $\begin{array}{c}\text { Ranga } \\
\text { Reddy,Karimnagar }\end{array}$ \\
\hline 9 & Ranga Reddy & $100.00 \%$ & 1.000 & 7 & 0 & \begin{tabular}{c} 
Ranga Reddy \\
\hline 10
\end{tabular} \\
\hline
\end{tabular}

From the above Table 3 we consider the bound $0.725 \leq Z^{*} \leq 1.000$ of the Technical Efficiency variation for the 23 districts. Out of 10 districts only Three has emerged as capable namely Ranga Reddy, Karimnagar, Hyderabad and the remaining 7 districts input loses due to Technical efficiency. Potential development is required in order to improve in their Performance with regards to results in Telangana State.

From the Table 3 it is understandable that RangaReddy, Karimnagar, Hyderabad are Technically (CCR) efficient when compared to the 10 districts. It is experiential that the Peers to the all other districts seem to be Ranga Reddy, Karimnagar, Hyderabad. Ranga Reddy district is having uppermost references. Peer contribution of this district is more comparable to other districts.

The Distribution of Scores Graph of Telangana for the Year 2013-14 is presented below:

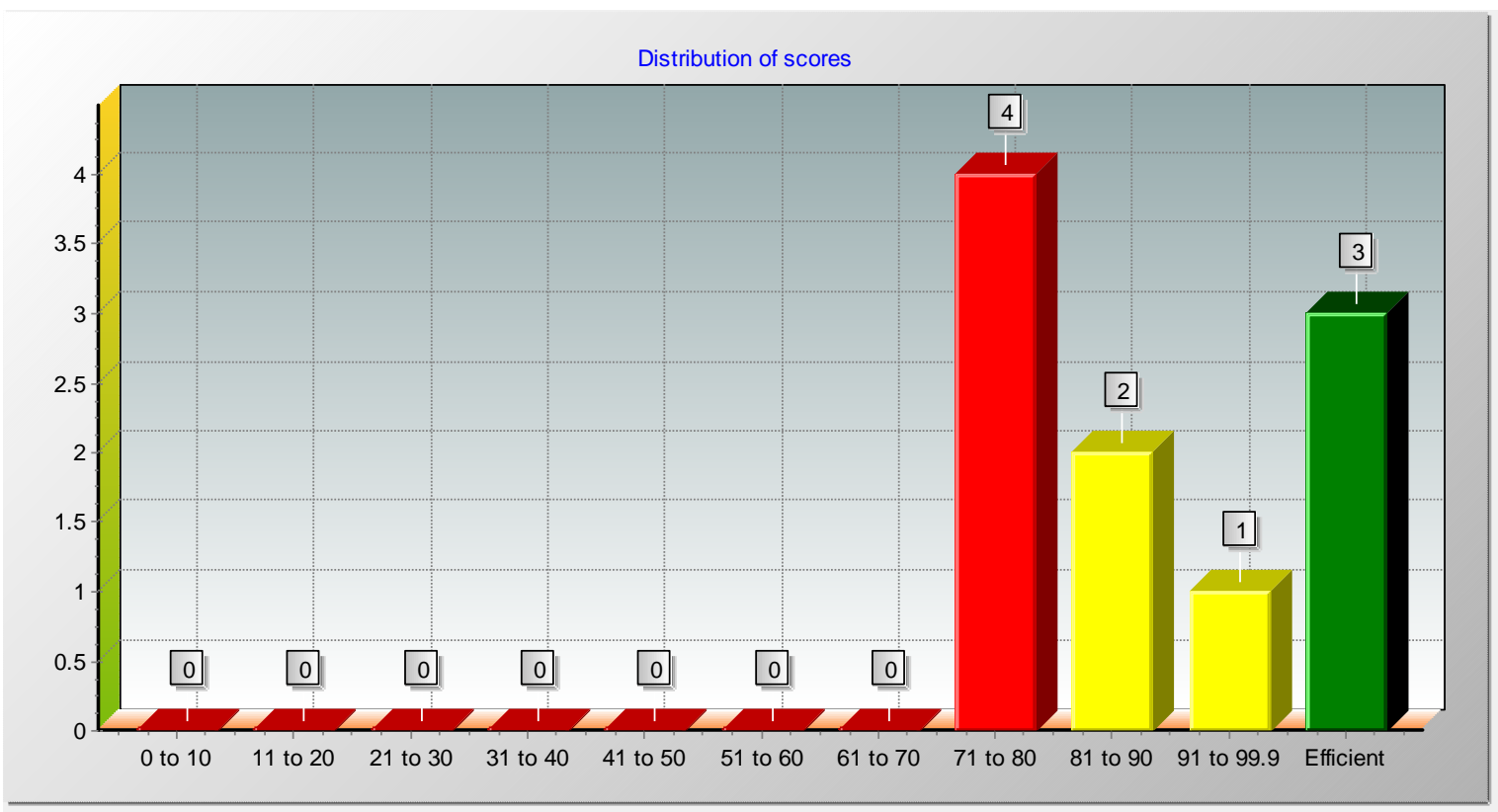

Figure 5. The Distribution of Scores Graph of Telangana State for the Year 2013-14

The following table for the two states and overall districts for the academic year 2013-14 is presented below for clarity. 
Naga Anuradha Chengalvala et al.

Table 4. Summary of Technical Efficiency (CCR) for the Year 2013-14

\begin{tabular}{|c|c|c|c|}
\hline & Overall & AP & TS \\
\hline Mean & 0.861 & 0.912 & 0.871 \\
\hline S.D & 0.097 & 0.056 & 0.114 \\
\hline C.V & 11.27 & 6.14 & 13.09 \\
\hline Minimum Efficiency & 0.668 & 0.848 & 0.725 \\
\hline Maximum Efficiency & 1 & 1 & 1 \\
\hline No. of Efficient districts & $\begin{array}{c}\text { 2(Krishna, West } \\
\text { Godavari) }\end{array}$ & 2(Krishna, West Godavari) & $\begin{array}{c}\text { 3(Ranga Reddy, } \\
\text { Karimnagar,Hyderabad) }\end{array}$ \\
\hline Total number of districts & 23 & 13 & 10 \\
\hline
\end{tabular}

\section{Conclusions}

From this analysis state of Andhra Pradesh performance is in first-rate. TS , AP as divided states ,we found that for the academic year Krishna, West Godavari performs well while no districts from Telangana perform well as Technical Efficiency. When it is separated as two states, the performance of TS have three districts namely Ranga Reddy, Karimnagar, Hyderabad. While the AP has Krishna, West Godavari district performed well.

\section{REFERENCES}

[1] Banker, R.D., R.F. Charnes, \& W.W. Cooper (1984) "Some Models for Estimating Technical and Scale Inefficiencies in Data Envelopment Analysis', Management Science vol. 30, pp. 1078-1092.

[2] Charnes, A , W. Cooper, \& E., Rhodes (1978) "Measuring the Efficiency of decision making units" European Journal of Operational Research vol. 2, pp. 429-444.

[3] Johnes, J., (1996) "Performance appraisal in higher Education in Britain"'European Journal of Operational Research vol. 2, pp. 18-33.

[4] Kwimbere, F.J. (1987). "Measuring efficiency in not-for-profit organizations: an attempt to assess the efficiency in selected UK university departments". M.Sc. thesis, School of Management, University of Bath.

[5] M. Goverdhan, Raju Nellutla, V. V Haragopal (2016) " A critical Data Envelopment Analysis of Hospital efficiency in India', International Journal of Scientific Research, Vol-5, issue2, pp.471475.

[6] Pina,V., Y Torres , L., (1995) "Analyse through DEA Teaching activity of the Account Department" in Spanish Public University.

[7] Raju Nellutla, V. V. Haragopal,(2015) "Data Envelopment Analysis of SSC Public Examinations 2009 -2011 of Andhra Pradesh"' Global Journal for Research Analysis, vol 4,issue 7,pp.141-144.

[8] Raju Nellutla, V. V Haragopal, (2015) "Performance of Management Schools in Secondary School Examinations of Andhra Pradesh State by Data Envelopment Analysis"' International Journal of Scientific Research, Vol-4,issue9, pp.179-182.

[9] Rhodes, E.Y. and Southwick, L. (1986) "Determinants of effectiveness in Public and Private Universities", Department of Economics, University of SouthCarolin.

[10] Rutter, M. \& Maughan, B. (2002) "School effectiveness findings 1970-2002 " Journal of School Psychology, vol.40, No.6, pp.451-475.

[11] Subramanyam, T., and C.S Reddy (2008) "Measuring the Risk Efficient in Indian Commercial Banking -DEA approach'” East West Journal of Economics and Business, Vol XI(1\&2) 76-105.

[12] Text book "Introduction to Data Envelopment Analysis and its Uses "by William W. Cooper, L M Seiford, Springer.

[13] http://bie.telangana.gov.in//

[14] http://bieap.gov.in// 